\title{
PARTICLE-LIKE ABSORPTION SPECTRA IN SMALL TRANSITION METAL CLUSTERS
}

\author{
Mark B. Knickelbein \\ Metal Cluster Chemistry Group, Chemistry Division \\ Argonne National Laboratory
}

Research at Argonne has found that small clusters of certain transition metal atoms display optical absorption spectra that are fundamentally different from those typically observed for other small molecules. A new laser technique known as photodissociation spectroscopy was used to record the absorption spectra of nickel clusters containing three to seven atoms and of niobium clusters containing between seven and twenty atoms. Instead of displaying spectra with distinct and separate absorption "bands" as is usually seen for small molecules, these metal clusters possess absorption spectra that are continuous and smooth throughout the visible and near ultraviolet regions, indicating that they absorb light at every wavelength. This behavior is in fact more like that displayed by much larger metal particles containing hundreds or thousands of atoms. This surprising result may indicate that the electronic structures of these small clusters are much closer to those of a corresponding macroscopic piece of nickel or niobium metal than was previously thought. This research, supported by the Department of Energy's Division of Chemical Sciences, was conducted by Mark Knickelbein and coworkers in Argonne's Metal Cluster Chemistry Group. These studies are aimed at understanding the electronic structure of the active metal cluster sites in catalysts, and may in addition provide valuable insights into the design and properties of new cluster assembled materials.

\section{DISCLAIMER}

This report was prepared as an account of work sponsored by an agency of the United States Government. Neither the United States Government nor any agency thereof, nor any of their employees, makes any warranty, express or implied, or assumes any legal liability or responsibility for the accuracy, completeness, or usefulness of any information, apparatus, product, or process disclosed, or represents that its use would not infringe privately owned rights. Reference herein to any specific commercial product, process, or service by trade name, trademark, manufacturer, or otherwise does not necessarily constitute or imply its endorsement, recommendation, or favoring by the United States Government or any agency thereof. The views and opinions of authors expressed herein do not necessarily state or reflect those of the United States Government or any agency thereof.

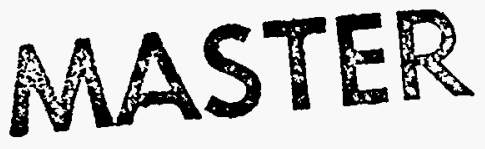




\section{DISCLAIMER}

Portions of this document may be illegible in electronic image products. Images are produced from the best available original document. 


\title{
PARTICLE-LIKE ABSORPTION SPECTRA IN SMALL TRANSITION METAL CLUSTERS
}

\author{
Mark B. Knickelbein \\ Metal Cluster Chemistry Group, Chemistry Division \\ Argonne National Laboratory
}

The optical absorption spectra of isolated transition metal clusters, $M_{n}$, have been obtained for the first time using a novel molecular beam method that employs pulsed lasers to photodissociate metal cluster-rare gas van der Waals complexes, $M_{n} R_{m}$. This method uses the loss of the weakly bound rare gas atom "tags" from the complexes as a signature of photon absorption by the underlying metal cluster. A "heating" of the complex occurs almost instantaneously after absorption of a single photon leading to loss of all rare gas atoms, a process that can be detected mass spectrometrically. Using this approach, the spectra of small nickel clusters and niobium clusters have been obtained throughout the visible and near ultraviolet regions.

These experiments employ a pump-probe spectroscopic technique in which a pulsed tunable pump laser intersects the molecular beam, inducing photodissociation in some fraction of the complexes. About $100 \mathrm{~ns}$ after the pump laser is fired, an ultraviolet probe laser is fired that ionizes the clusters and complexes within the same volume of the molecular beam intersected by the pump laser. Detection of these ions is accomplished by time-of-flight (TOF) mass spectrometry, an example of which is shown in the top trace of Fig. 1 for niobium clusters and their argon complexes obtained using the $193 \mathrm{~nm}$ probe laser only. Photoabsorption by the complexes is measured by collecting two TOF mass spectra concurrently, a reference spectrum obtained using the probe (photoionization) laser only, and a depletion spectrum obtained with the pump laser fired prior to the probe laser. As seen in the bottom trace of Fig. 1, the pump+probe TOF mass spectrum demonstrates a significant depletion of the $\mathrm{Nb}_{n} \mathrm{Ar}_{\mathrm{m}}$ species and a corresponding increase in the $\mathrm{Nb}_{n}$, showing that all complexes in this 
size range absorb at the pump laser wavelength of $440 \mathrm{~nm}$. The measured NbnArm mass peak depletion when combined with knowledge of the pump laser intensity yields an absorption cross section for each wavelength. Spectra are composed of discrete photodissociation cross section measurements recorded at many closely spaced wavelength intervals. The photodissociation spectra for selected niobium cluster complexes $\mathrm{Nb}_{n} \mathrm{Ar}$ are shown in Fig. 2.

The niobium cluster spectra are observed to be qualitatively similar to one another and even for the smallest clusters remarkably "nonmolecular". Instead of being composed of distinct absorption bands corresponding to different excited electronic states, these spectra are continuous, with cross section that increase steadily with decreasing wavelength. In fact, as shown in Fig. 2, the shapes of these absorption spectra are in qualitative accord with those predicted by a classical electrodynamic theory developed by Mie in 1908 to account for absorption and scattering of light by small, spherical metal particles. Although this result does not necessarily imply that these small clusters possess bulk-like properties, it does reinforce the long-held notion that transition metal clusters, even those composed of only a few atoms, possess a great number of excited electronic states that are so closely spaced that they are spectroscopically unresolvable. Spectra recently obtained by this group for small nickel clusters are similar to the niobium cluster results, with even the nickel trimer lacking distinct absorption bands.

We anticipate that these studies will help us understand the electronic structure of catalysts and, in addition, may provide valuable insights into the design and properties of new cluster assembled materials.

\section{Acknowledgment}

This work was supported by the United States Department of Energy, Office of Basic Energy Sciences, Division of Chemical Sciences, under contract W-31-109-ENG-38. 


\section{$\mathrm{Nb}_{n} \mathrm{Ar}_{\mathrm{m}}$}

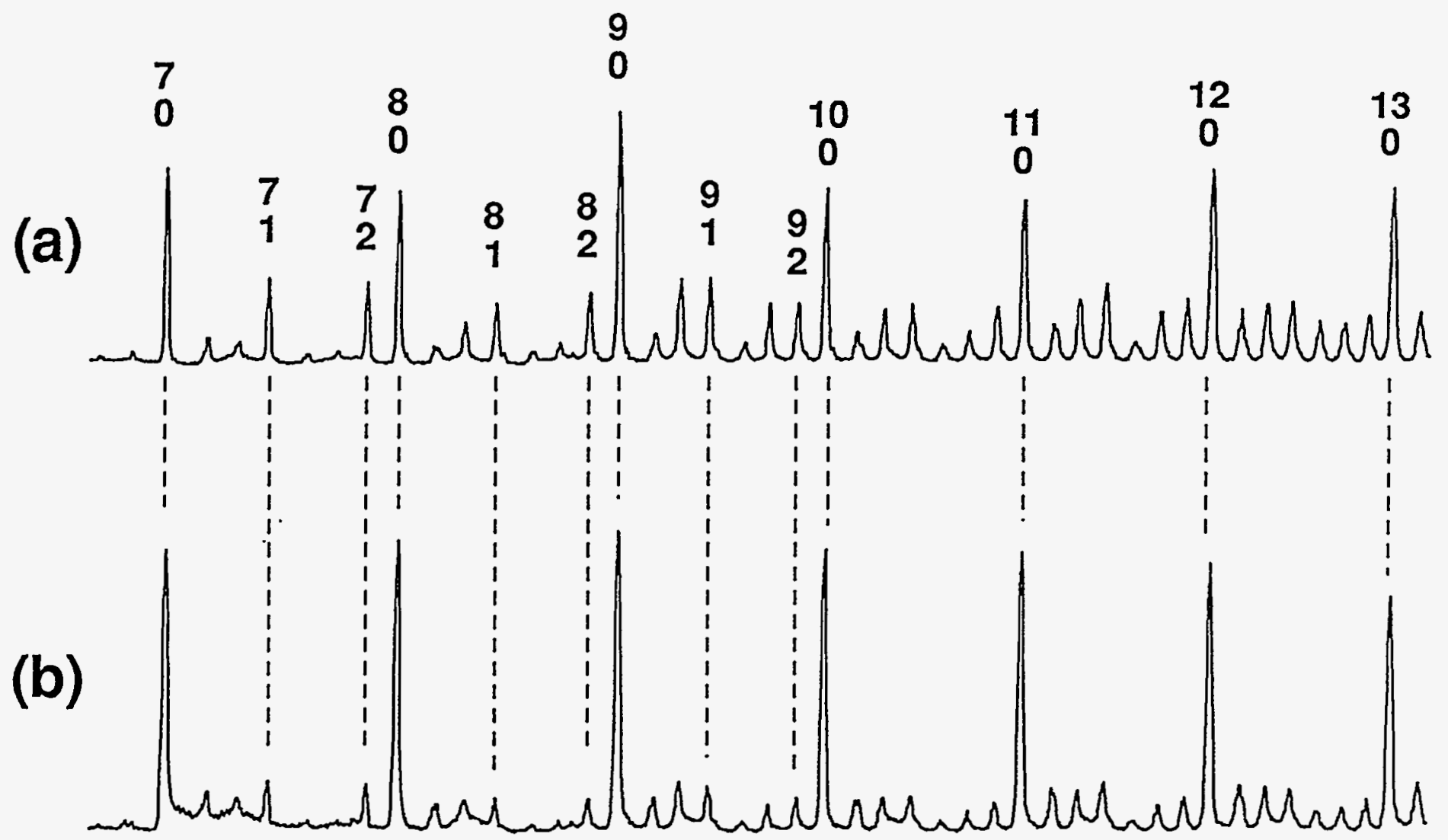

Fig. 1. Time-of-flight mass spectra for niobium clusters $\mathrm{Nb}_{\mathrm{n}}$ and their corresponding argon van der Waals complexes $\mathrm{Nb}_{n} \mathrm{Ar}_{\mathrm{m}}$. (a) Reference spectrum obtained with probe laser $(\lambda=193 \mathrm{~nm})$ only. (b) Depletion spectrum recorded at a pump laser wavelength of $440 \mathrm{~nm}$. 


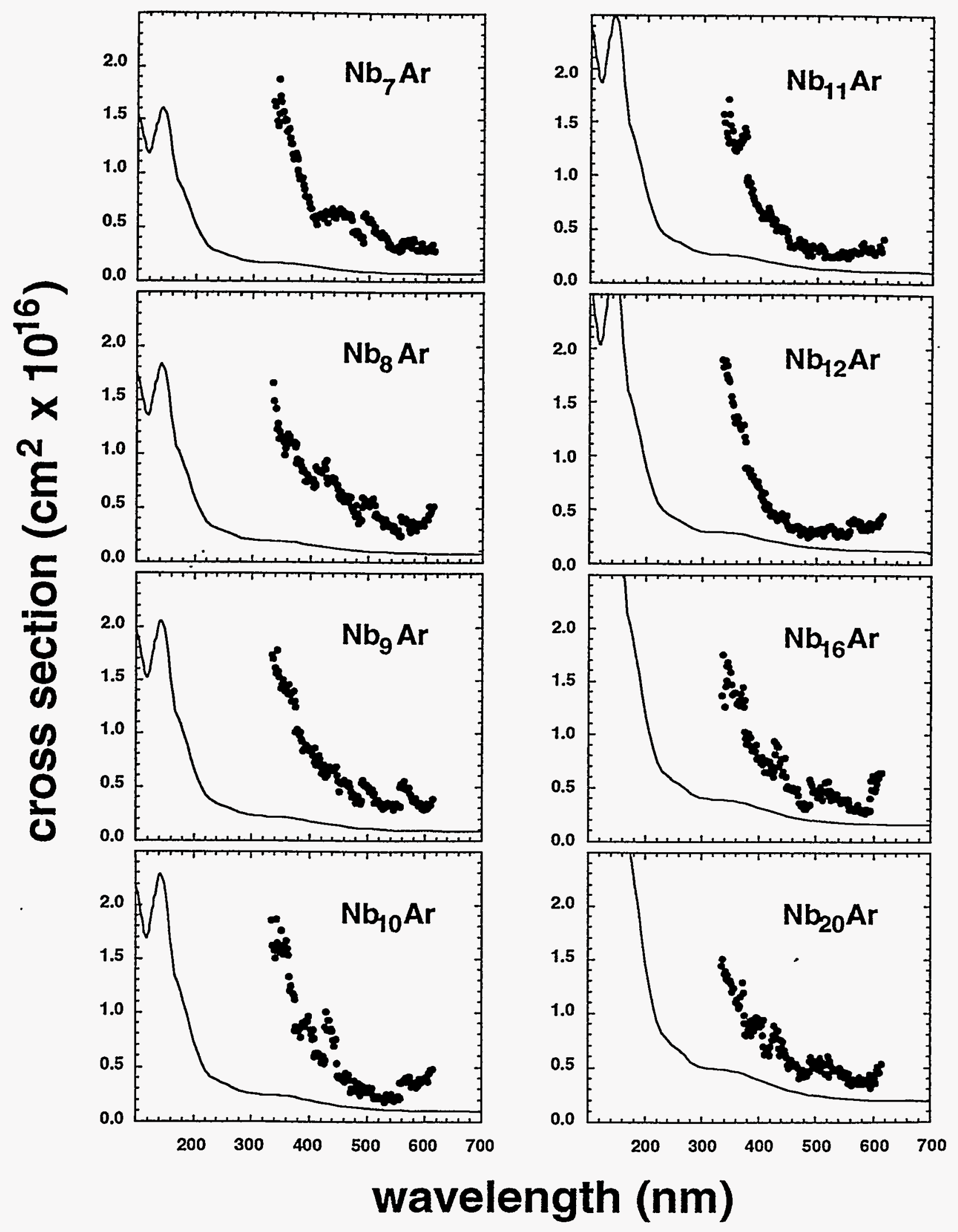

Fig. 2. Absorption spectra of selected niobium clusters from $634 \mathrm{~nm}$ to $614 \mathrm{~nm}$ obtained by photodissociation of their corresponding argon van der Waals complexes along with theoretical predictions of the Mie model (solid curves). 